\title{
Renal Function Predicts Survival in Patients with Acute Ischemic Stroke
}

\author{
Elizabeth Mostofsky ${ }^{a, c}$ Gregory A. Wellenius ${ }^{a}$ Amit Noheria $^{a}$ Emily B. Levitan ${ }^{a}$ \\ Mary R. Burger ${ }^{a}$ Gottfried Schlaug ${ }^{b}$ Murray A. Mittleman ${ }^{a, c}$ \\ ${ }^{a}$ Cardiovascular Epidemiology Research Unit, Department of Medicine, and ${ }^{b}$ Division of Cerebrovascular Disease, \\ Department of Neurology, Beth Israel Deaconess Medical Center, Harvard Medical School, and ${ }^{\mathrm{C}}$ Department of \\ Epidemiology, Harvard School of Public Health, Boston, Mass., USA
}

\section{Key Words}

Creatinine $\cdot$ Glomerular filtration rate $\cdot$ Renal disease $\cdot$

Cerebrovascular disease $\cdot$ Mortality

\begin{abstract}
Background: Among patients with acute ischemic stroke, impaired kidney function has been shown to increase the mortality risk, but the shape of this relationship has not been evaluated in detail. Methods: We estimated the glomerular filtration rate (eGFR) at the time of hospitalization in 1,175 consecutive patients hospitalized with acute ischemic stroke at the Beth Israel Deaconess Medical Center and examined the shape of the association between eGFR and all-cause mortality. Results: There were 508 deaths during a median follow-up of 40.3 months, resulting in a ' $U$ '-shaped relationship between eGFR and all-cause mortality. The curve was relatively flat between 75 and $110 \mathrm{ml} / \mathrm{min} / 1.73 \mathrm{~m}^{2}$ but increased sharply at lower and higher levels of eGFR (test for nonlinearity: $p<0.0001)$. Conclusions: Among patients with acute ischemic stroke, a reduced or highly elevated eGFR at hospital admission is associated with a higher mortality rate compared to patients with moderate levels of eGFR.
\end{abstract}

Copyright $\odot 2009$ S. Karger AG, Basel

\section{KARGER}

Fax +41613061234

E-Mail karger@karger.ch

www.karger.com (c) 2009 S. Karger AG, Base

Accessible online at:

www.karger.com/ced
Stroke is the third leading cause of death in the USA after heart disease and cancer, and the leading cause of serious, long-term disability, with an estimated direct and indirect cost of USD 65.5 billion for 2008 [1]. According to the Atherosclerosis Risk in communities study [2], $8-12 \%$ of ischemic stroke patients $45-64$ years of age die within 30 days, and $>30 \%$ of the people $40-69$ years of age die within 5 years of their first stroke [1]. Recent evidence suggests that reduced kidney function may predict survival after acute ischemic stroke independently of classic risk factors [3-5], but the shape of this relationship has not been explored. While Shlipak et al. [6] found that among the elderly, the association between creatinine and mortality is J-shaped, this connection has not been examined among ischemic stroke patients. Therefore, we studied the shape of the relationship between kidney function and mortality with the Modification of Diet in Renal Disease (MDRD) equation to estimate the glomerular filtration rate (eGFR), an approach that is widely used but, like serum creatinine, may give falsely high estimates of kidney function in the presence of low muscle mass [7].

Using eGFR to identify a high-risk subgroup may improve poststroke survival by targeting renal factors that impact vascular health. Accordingly, we examined the shape and magnitude of the relationship between renal

Tel. +1 617667 3184, Fax +1 617632 7698, E-Mail mmittlem@bidmc.harvard.edu 
function and mortality among 1,175 consecutive patients hospitalized for acute ischemic stroke at the Beth Israel Deaconess Medical Center (BIDMC) from the Boston metropolitan region.

\section{Materials and Methods}

\section{Study Population}

This study was approved by the Committee on Clinical Investigations at the BIDMC. We identified consecutive patients $\geq 21$ years of age admitted to the BIDMC between April 1, 1999, and December 31, 2004, with neurologist-confirmed ischemic cerebrovascular disease and residing in the Boston metropolitan region. The patients' medical records were reviewed by trained abstractors to confirm the diagnosis of acute ischemic stroke. $\mathrm{Pa}$ tients with in-hospital strokes or transient ischemic attacks were excluded from further analysis. A coinvestigator (G.S.) arbitrated if the final diagnosis was unclear. For each case, trained abstractors using standardized forms recorded data on patient demographics, presenting symptoms and medical history from patient charts or electronic medical records. Race was categorized as white, African-American or other. History of stroke, coronary artery disease, myocardial infarction, atrial fibrillation, heart failure, valvular heart disease, diabetes and dyslipidemia were recorded as present if noted in the medical records and absent otherwise. For each case, the presumed stroke etiology was evaluated as cardioembolic, small-vessel, large-vessel or other/undetermined according to modified TOAST criteria [8].

\section{Renal Function}

Data on serum creatinine drawn at the time of hospital presentation were collected. Serum creatinine was measured by the clinical chemistry laboratory photometrically using the Jaffe reaction, with a coefficient of variation of $6.4 \%$ at the level of 0.7 $\mathrm{mg} / \mathrm{dl}$ and $2.2 \%$ at the level of $5.6 \mathrm{mg} / \mathrm{dl}$. We calculated the eGFR using the abbreviated MDRD equation [9] as follows:

$$
\begin{aligned}
& e G F R=186 \times S_{c r}-1.154 \times \text { age } \\
& (1.210 \text { if African-American }),
\end{aligned}
$$

where $e G F R$ is the estimated glomerular filtration rate in milliliters/minute/1.73 square meters, $S c r$ is the serum creatinine concentration in milligrams/deciliter and age is in years. This formula was originally developed using data on $>1,000$ patients with various kidney diseases and it was validated on an additional 500 patients [10].

\section{Outcome Assessment}

Vital status was obtained from the US Social Security Death Index $[11,12]$. Registry records were linked to the death data on the basis of key identifiers including patient name, date of birth, social security number and gender. The Social Security Death Index data were obtained on March 20, 2007.

\section{Statistical Analysis}

We report univariate statistics stratified by levels of kidney function as mean \pm standard deviation or as counts with proportions, as appropriate. Cox proportional hazards models were used to estimate the hazard ratio for all-cause mortality adjusting for age (continuous) and sex and stratifying on calendar year. To examine whether the association between kidney function and mortality changes in a nonlinear fashion across the full range of eGFR, we modeled eGFR as a continuous variable using penalized splines [13] adjusting for age, sex and race. A priori, we selected 3 degrees of freedom based on biologic plausibility. This choice was consistent with that chosen by the software to minimize the Akaike Information Criterion for the fitted model.

For consistency with prior publications, we also created 4 categories of renal function and estimated the association between kidney function and mortality. Those with an eGFR between 75 and $125 \mathrm{ml} / \mathrm{min} / 1.73 \mathrm{~m}^{2}$ were compared to people with an eGFR $<60 \mathrm{ml} / \mathrm{min} / 1.73 \mathrm{~m}^{2}$, those with an eGFR between 60.0 and 74.9 $\mathrm{ml} / \mathrm{min} / 1.73 \mathrm{~m}^{2}$ and those with an eGFR $>125 \mathrm{ml} / \mathrm{min} / 1.73 \mathrm{~m}^{2}$. These categories were chosen a priori based on the Valsartan in Acute Myocardial Infarction Trial, which used these eGFR cutoffs in 14,527 patients with cardiovascular disease [14], with an additional category to examine the risk among patients who may have a falsely elevated eGFR due to low muscle mass.

We constructed a multivariate model additionally controlling for race (African-American, white or other), smoking status (never, former, current), and medical history of stroke, coronary artery disease, myocardial infarction, atrial fibrillation, heart failure, valvular disease, diabetes, dyslipidemia and hypertension. We did not adjust for stroke severity, treatment received during the index hospitalization or medications and lifestyle factors following stroke [15-17] in the primary analyses, since these factors may be downstream consequences occurring after the development of reduced or highly elevated eGFR. In sensitivity analyses we additionally controlled for correlates of stroke severity. Although standard measures of stroke severity were not routinely documented in the medical records, we used the number of presenting symptoms ( $\geq 4$ vs. $<4$ ), length of hospital stay ( $\geq 4$ vs. $<4$ days), disposition (home vs. other) and stroke etiology (4 categories) as proxy measures of stroke severity. For tests of quadratic trend, we assigned median eGFR to each category, centered it on mean eGFR and tested for significance using a likelihood ratio test.

We evaluated whether the association between eGFR and mortality differed by sex, age ( $<75$ vs. $\geq 75$ years), smoking status or 30-day survival by including interaction terms in the model adjusted for age, sex and race. We verified the proportional hazards assumption using interactions of the predictors and a function of survival time and found no significant violations. We conducted sensitivity analyses excluding Asians (2\%) because the MDRD formula does not perform well in Asian populations and patients meeting the criteria for renal replacement therapy (2\%), but the results were not materially different. All analyses were carried out using SAS 9.1 (SAS Institute, Inc., Cary, N.C., USA) and $R$ 2.6.2. Two-sided $p$ values $<0.05$ were considered statistically significant.

\section{Results}

We identified 1,180 consecutive patients hospitalized for neurologist-confirmed acute ischemic stroke. Data on serum creatinine at the time of hospital presentation were 
Table 1. Baseline characteristics of 1,175 patients with ischemic stroke by eGFR

\begin{tabular}{|c|c|c|c|c|c|}
\hline & $\begin{array}{l}<60.0 \\
\mathrm{ml} / \mathrm{min} / 1.73 \mathrm{~m}^{2} \\
(\mathrm{n}=391)\end{array}$ & $\begin{array}{l}60.0-74.9 \\
\mathrm{ml} / \mathrm{min} / 1.73 \mathrm{~m}^{2} \\
(\mathrm{n}=296)\end{array}$ & $\begin{array}{l}75.0-125.0 \\
\mathrm{ml} / \mathrm{min} / 1.73 \mathrm{~m}^{2} \\
(\mathrm{n}=434)\end{array}$ & $\begin{array}{l}>125.0 \\
\mathrm{ml} / \mathrm{min} / 1.73 \mathrm{~m}^{2} \\
(\mathrm{n}=54)\end{array}$ & $\begin{array}{l}\mathrm{p} \\
\text { value }\end{array}$ \\
\hline Age, years & $77.9 \pm 10.7$ & $76.9 \pm 13.1$ & $67.6 \pm 14.4$ & $58.0 \pm 15.4$ & $<0.0001$ \\
\hline Serum creatinine, $\mathrm{mg} / \mathrm{dl}$ & $1.80 \pm 1.39$ & $0.98 \pm 0.16$ & $0.81 \pm 0.15$ & $0.58 \pm 0.09$ & $<0.0001$ \\
\hline Creatinine level within reference range & $91(24)$ & $286(97)$ & $432(99)$ & $54(100)$ & $<0.0001$ \\
\hline Female & $234(60)$ & $179(60)$ & $205(47)$ & $26(48)$ & 0.0003 \\
\hline African-American & $43(11)$ & $17(6)$ & $54(12)$ & $10(19)$ & 0.0056 \\
\hline Current smokers & $36(9)$ & $38(13)$ & $70(16)$ & $24(44)$ & $<0.0001$ \\
\hline Former smokers & $101(26)$ & $71(24)$ & $110(25)$ & $13(24)$ & 0.93 \\
\hline \multicolumn{6}{|l|}{ History of } \\
\hline Stroke & $142(36)$ & $82(28)$ & $103(24)$ & $10(19)$ & 0.0002 \\
\hline Coronary artery disease & $144(37)$ & $73(25)$ & $89(21)$ & $6(11)$ & $<0.0001$ \\
\hline Myocardial infarction & $63(16)$ & $35(12)$ & $47(11)$ & $5(9)$ & 0.1012 \\
\hline Atrial fibrillation & $119(30)$ & $66(22)$ & $88(20)$ & $6(11)$ & 0.0005 \\
\hline Heart failure & $76(19)$ & $32(11)$ & $31(7)$ & $3(6)$ & $<0.0001$ \\
\hline Valvular heart disease & $13(3)$ & $3(1)$ & $2(0.5)$ & $1(2)$ & 0.0093 \\
\hline Diabetes & $152(39)$ & $73(25)$ & $111(26)$ & $19(35)$ & $<0.0001$ \\
\hline Dyslipidemia & $165(42)$ & $106(36)$ & $155(36)$ & $13(24)$ & 0.0321 \\
\hline Hypertension & $305(78)$ & $220(74)$ & $272(63)$ & $29(54)$ & $<0.0001$ \\
\hline Length of stay, days & $5.3 \pm 4.7$ & $5.0 \pm 3.7$ & $5.1 \pm 4.9$ & $5.5 \pm 5.1$ & 0.71 \\
\hline Discharge & & & & & 0.0008 \\
\hline Home & $147(38)$ & $110(37)$ & $220(51)$ & $30(56)$ & \\
\hline Rehabilitation facility & $63(16)$ & $52(18)$ & $66(15)$ & $8(15)$ & \\
\hline Skilled nurse facility & $74(19)$ & $59(20)$ & $57(13)$ & $5(9)$ & \\
\hline Dead & $31(8)$ & $14(5)$ & $13(3)$ & $1(2)$ & \\
\hline Other & $76(19)$ & $61(21)$ & $78(18)$ & $10(19)$ & \\
\hline Stroke etiology & & & & & 0.78 \\
\hline Small-vessel & $105(27)$ & $91(31)$ & $128(29)$ & $15(28)$ & \\
\hline Large-vessel & $82(21)$ & $74(25)$ & $95(22)$ & $11(21)$ & \\
\hline Cardioembolic & $90(23)$ & $54(18)$ & $92(21)$ & $10(19)$ & \\
\hline Other/undetermined & $114(29)$ & $77(26)$ & $119(27)$ & $18(33)$ & \\
\hline
\end{tabular}

Figures are means \pm standard deviation or numbers of cases with percentages in parentheses. $\mathrm{p}$ values for discrete variables derived from $\chi^{2}$ tests and continuous variables from ANOVA. Serum creatinine reference ranges for the BIDMC laboratory: 0.5$1.2 \mathrm{mg} / \mathrm{dl}$ for males and $0.4-1.1 \mathrm{mg} / \mathrm{dl}$ for females.

available in $99.6 \%(\mathrm{n}=1,175)$ of the patients. The mean eGFR upon presentation was $72 \mathrm{ml} / \mathrm{min} / 1.73 \mathrm{~m}^{2}$ (standard deviation 28.2) with $36.9 \%(n=434)$ of the patients presenting with an eGFR between 75 and $125 \mathrm{ml} / \mathrm{min} /$ $1.73 \mathrm{~m}^{2}$ and $33.3 \%(\mathrm{n}=391)$ with a value $<60 \mathrm{ml} / \mathrm{min} /$ $1.73 \mathrm{~m}^{2}$. Ninety-seven percent $(\mathrm{n}=286)$ of the patients with an eGFR between 60 and $75 \mathrm{ml} / \mathrm{min} / 1.73 \mathrm{~m}^{2}$ and $24 \%(\mathrm{n}=91)$ of those with an eGFR $<60 \mathrm{ml} / \mathrm{min} / 1.73 \mathrm{~m}^{2}$ had creatinine values within the normal range for the BIDMC clinical chemistry laboratory $(0.5-1.2 \mathrm{mg} / \mathrm{dl}$ for males and $0.4-1.1 \mathrm{mg} / \mathrm{dl}$ for females). Patients in the lowest category of eGFR were more likely to be female and more likely to have experienced previous cardiovascular diseases than those in the reference category (table 1).
During a median follow-up of 40.3 months, 508 of the 1,175 participants (43\%) died.

We used Cox proportional hazard models with penalized splines to evaluate the shape of the relationship between eGFR and all-cause mortality, adjusting for age and sex. There was a ' $U$ '-shaped association between eGFR and all-cause mortality, with a nadir at approximately $85 \mathrm{ml} / \mathrm{min} / 1.73 \mathrm{~m}^{2}$ (fig. 1 ). The curve was relatively flat between 75 and $110 \mathrm{ml} / \mathrm{min} / 1.73 \mathrm{~m}^{2}$ but increased sharply at lower and higher levels of eGFR (test for nonlinearity: $\mathrm{p}<0.0001$ ).

For comparison with prior studies, we also modeled the eGFR using 4 categories. Table 2 shows that after adjusting for age and sex there was a graded increase in all- 
Fig. 1. Penalized spline fit showing the hazard ratio of all-cause mortality as a function of eGFR among 1,175 patients with ischemic stroke. Data were fitted using a penalized spline Cox proportional hazards model adjusted for age and sex. The solid line represents the hazard ratio and the dashed lines the 95\% confidence interval bands. The distribution of eGFR is displayed as vertical lines below the plot.

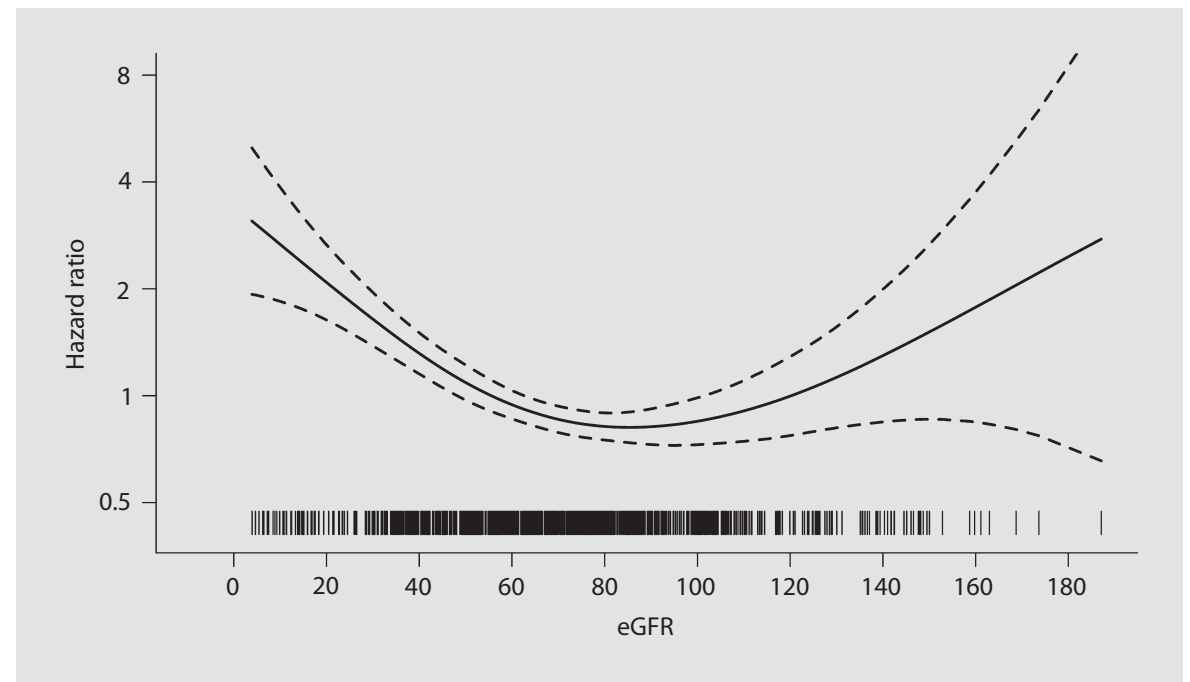

Table 2. Hazard ratio for impaired kidney function and all-cause mortality among 1,175 patients with ischemic stroke

\begin{tabular}{lll}
\hline eGFR & $\begin{array}{l}\text { Age- and } \\
\text { sex-adjusted }\end{array}$ & $\begin{array}{l}\text { Fully } \\
\text { adjusted }\end{array}$ \\
\hline$<60.0 \mathrm{ml} / \mathrm{min} / 1.73 \mathrm{~m}^{2}$ & $1.54(1.23-1.92)$ & $1.48(1.17-1.86)$ \\
$60.0-74.9 \mathrm{ml} / \mathrm{min} / 1.73 \mathrm{~m}^{2}$ & $1.10(0.86-1.41)$ & $1.21(0.94-1.55)$ \\
$75-125 \mathrm{ml} / \mathrm{min} / 1.73 \mathrm{~m}^{2}$ & $1.0($ reference) & 1.0 (reference) \\
$>125 \mathrm{ml} / \mathrm{min} / 1.73 \mathrm{~m}^{2}$ & $1.63(0.95-2.80)$ & $1.66(0.96-2.88)$ \\
p quadratic trend & 0.002 & 0.01 \\
\hline
\end{tabular}

Figures in parentheses are 95\% CI. Fully adjusted: adjusted for age, sex, race, smoking status (never, former, current), previous stroke, coronary artery disease, myocardial infarction, atrial fibrillation, heart failure, valve disease, diabetes, dyslipidemia and hypertension.

cause mortality with decreasing kidney function ( $p$ for quadratic trend $=0.002$ ). In a fully adjusted model that also accounted for race, smoking status, diabetes, dyslipidemia, hypertension, coronary artery disease, myocardial infarction, atrial fibrillation, heart failure, valve disease and previous stroke, we found that compared to patients with an eGFR between 75 and $125 \mathrm{ml} / \mathrm{min} / 1.73 \mathrm{~m}^{2}$, the all-cause mortality rate was $21 \%$ higher among patients with an eGFR between 60.0 and $74.9 \mathrm{ml} / \mathrm{min} /$ $1.73 \mathrm{~m}^{2}, 48 \%$ higher among those with an eGFR $<60 \mathrm{ml} /$ $\min / 1.73 \mathrm{~m}^{2}$ and $66 \%$ higher among patients with an $\mathrm{eGFR}>125 \mathrm{ml} / \mathrm{min} / 1.73 \mathrm{~m}^{2}$ ( $\mathrm{p}$ for quadratic trend $=0.01$ ). The results were not materially different upon further adjustment for stroke symptoms, length of stay, disposition or presumed stroke etiology. The hazard ratios for the association between eGFR and mortality did not vary by sex ( $\mathrm{p}=0.48)$, age $\geq 75$ versus age $<75(\mathrm{p}=0.61)$ or smoking status $(\mathrm{p}=0.84)$. The hazard ratios were also not significantly different in the first 30 days versus during the remainder of the follow-up time $(\mathrm{p}=0.30)$.

Of the 1,175 patients hospitalized, 119 (10.1\%) died within 30 days of hospitalization. Adjusting for age, sex and comorbidities, the 30-day case fatality rate was $61 \%$ (95\% CI: 1.00-2.60) higher among patients with an eGFR $<60.0 \mathrm{ml} / \mathrm{min} / 1.73 \mathrm{~m}^{2}$ as compared to those with an eGFR between 75 and $125 \mathrm{ml} / \mathrm{min} / 1.73 \mathrm{~m}^{2}$. Patients with an eGFR between 60.0 and $74.9 \mathrm{ml} / \mathrm{min} / 1.73 \mathrm{~m}^{2}$ were not at increased risk of 30-day mortality [hazard ratio (HR): 1.0; $95 \%$ CI: $0.6-1.7]$. Only 1 patient with an eGFR $>125$ $\mathrm{ml} / \mathrm{min} / 1.73 \mathrm{~m}^{2}$ died within 30 days.

\section{Discussion}

In the present study, we sought to determine whether the eGFR in patients hospitalized with acute ischemic stroke provided prognostic information about mortality. Because the eGFR can be falsely elevated in the presence of low muscle mass, we hypothesized that patients with an eGFR $>125 \mathrm{ml} / \mathrm{min} / 1.73 \mathrm{~m}^{2}$ would also be at elevated risk. We observed a ' $U$ '-shaped relationship between eGFR and all-cause mortality, with increased risk among those with both low and high levels of eGFR. This was confirmed in an analysis using categories of exposure, which indicated an elevated risk among patients with an 
eGFR $<75 \mathrm{ml} / \mathrm{min} / 1.73 \mathrm{~m}^{2}$ and an apparent elevated risk among patients with an eGFR $>125 \mathrm{ml} / \mathrm{min} / 1.73 \mathrm{~m}^{2}$ that did not reach statistical significance, independent of age, sex, race and major comorbidities.

Impaired renal function is an established predictor of survival in the general population [18], in patients with myocardial infarction [14, 19-21] or heart failure [22, 23], and those undergoing percutaneous cardiovascular interventions [24] or coronary artery bypass graft surgery [25-27]. However, whether chronic kidney disease predicts survival following acute ischemic stroke, has not been extensively studied. Zuliani et al. [28] found no association between serum creatinine and 30-day mortality among 469 stroke patients $\geq 65$ years of age. In contrast, Macwalter et al. [4] followed 2,042 stroke patients in Scotland and found that creatinine clearance, urea, creatinine concentration, and ratio of urea all predicted survival over 7 years of follow-up. For instance, a creatinine clearance between 51.26 and $66.75 \mathrm{ml} / \mathrm{min} / 1.73 \mathrm{~m}^{2}$ was significantly associated with a $30 \%$ decrease in mortality compared to those with a creatinine clearance in the lowest quartile, even after adjustment for other risk factors (relative risk: 0.70; 95\% CI: 0.53-0.92). Similarly, in a case-control study of 545 white Europeans and 330 age-matched controls, Carter et al. [3] demonstrated a significantly increased risk of mortality among stroke patients across baseline creatinine levels (HR: 1.85; 95\% CI: $1.25-2.73 ; \mathrm{p}=0.002$ ). The results of the current study confirm the finding that reduced eGFR is associated with increased mortality among stroke patients and shows that this relationship changes in a nonlinear fashion across the full range of eGFR values.

Participants with chronic diseases may have an elevated eGFR that does not reflect proper kidney function. Similar to our findings, Shlipak et al. [6] showed that the association between quintiles of creatinine and mortality from all causes appeared to be J-shaped among 4,637 participants in the Cardiovascular Health Study, and Inrig et al. [29] found an elevated risk of cardiovascular outcomes among patients with atherosclerotic cardiovascular disease who had an eGFR $\geq 125 \mathrm{ml} / \mathrm{min} / 1.73 \mathrm{~m}^{2}$. This may be due to the fact that eGFR is often falsely elevated among patients with grossly abnormal muscle mass (e.g. amputation, paralysis, muscular disease), low body mass index $(<18.5)$, high or low intake of creatinine or creatine (e.g. dietary supplements, vegetarians), concomitant medication use and rapidly changing kidney function $[7,29,30]$.

Interpretations of creatinine levels alone are not sufficient for risk stratification. The eGFR must decline to approximately half the normal level before the serum creatinine concentration rises above the upper limit of normal. An eGFR $<60 \mathrm{ml} / \mathrm{min} / 1.73 \mathrm{~m}^{2}$ represents loss of half or more of the adult level of normal kidney function and is associated with an increased prevalence of complications of chronic kidney disease [10], yet one quarter of the patients in this sample with an eGFR $<60 \mathrm{ml} / \mathrm{min} /$ $1.73 \mathrm{~m}^{2}$ had creatinine levels in the normal range.

The relationship between kidney function and survival following an acute ischemic stroke may be due to shared risk factors underlying vascular diseases including age, diabetes mellitus, systolic hypertension, left ventricular hypertrophy and low high-density lipoprotein cholesterol [31], or it may represent a unique vascular pathogenesis resulting from reduced renal clearance [32]. Kidney function may be a marker of other predictors of mortality, such as end-organ damage from subclinical hypertension. Alternatively, kidney function may be associated with arterial stiffness and thus pose an increased risk of cardiovascular morbidity and mortality [33]. Based on MRI results from 484 participants from the Rotterdam Scan Study, Ikram et al. [34] found that impaired kidney function is associated with MRI markers of cerebral small-vessel disease and suggested that this relationship may be due to the fact that the blood vessels of both the kidney and the brain have low resistance and are therefore highly susceptible to fluctuations in blood pressure and flow.

Our findings are based on creatinine measurements at the time of hospital admission, but other studies suggest that there is an association between decreased kidney function during the hospital stay and in-hospital mortality [35] and major bleeding [36] after ischemic stroke. Changes during hospitalization also independently predict the 1-year mortality after acute myocardial infarction [19, 37]. Goldberg et al. [19] examined the relation between baseline creatinine clearance and worsening renal function, defined as an increase of $\geq 0.5 \mathrm{mg} / \mathrm{dl}$ in creatinine level at any point during hospital stay, and subsequent in-hospital and 1-year mortality among patients presenting with acute ST elevation myocardial infarction. The authors found that both baseline renal dysfunction (HR: 2.8 ; 95\% CI: 1.6-4.9) and worsening renal function (HR: 7.2; 95\% CI: 4.9-10.4) remained independent predictors of 1-year mortality. Thus, in-hospital changes in eGFR may also predict poststroke survival. However, in our cohort there were too few patients with repeat creatinine measurement to evaluate this association.

This study has some limitations that warrant discussion. First, all patients were admitted to a single center 
and resided in the same metropolitan area with relatively few African-Americans, possibly limiting the generalizability of these findings. Second, there may have been misclassification of the outcome due to errors in the death records of the Social Security Administration. However, this database has been shown to serve as a valid source of mortality data $[11,12]$. Third, the MDRD formula does not perform well in Asian populations [38], but the majority of our cohort were white, with only $2 \%$ Asian. In a sensitivity analysis excluding Asian patients, the results were similar. Fourth, standard measures of stroke severity were not available. However, in sensitivity analyses controlling for various correlates of stroke severity, the results were not materially different. Finally, some patients may have had elevated creatinine levels requiring intensive treatment for kidney impairment, which could be associated with prognosis. However, only $2 \%$ of the sample had an eGFR between 15 and $29 \mathrm{ml} / \mathrm{min} / 1.73 \mathrm{~m}^{2}$, the recommended cutoff for the preparation of renal replacement therapy [10], and only $2 \%$ had an eGFR $<15$ $\mathrm{ml} / \mathrm{min} / 1.73 \mathrm{~m}^{2}$, the recommended cutoff for the initiation of dialysis. Therefore, any increasing mortality from treatment seems minimal. In a sensitivity analysis excluding patients meeting the criteria for renal replacement therapy, the results were similar to those in the primary analysis. This study has many strengths, including an examination of a nonlinear association, a large sample of unselected patients, detailed clinical data and consistent high-quality follow-up data.

\section{Conclusion}

The severity of impaired kidney function in patients hospitalized with acute ischemic stroke is associated with increased all-cause mortality independent of age, sex, race and major comorbidities. These results also indicate that creatinine levels must be used cautiously. Even patients with only mildly reduced kidney function, who often have creatinine levels within the normal reference range for many clinical chemistry laboratories, are at increased risk. Similarly, patients with low muscle mass may have creatinine levels indicative of normal kidney function when indeed they are at increased risk. The eGFR is easy to calculate and may serve as a useful tool for risk stratification of these patients. Therapeutic studies are required to determine whether novel or established secondary prevention measures are particularly efficacious among these high-risk patients.

\section{Acknowledgements and Funding}

The project described was supported by grants No. ES013804, ES009825 and ES015774 from the National Institute of Environmental Health Sciences, NIH. E.B.L. was supported by grant No. F32HL091683 from the Nation Heart, Lung and Blood Institute, NIH. Its contents are solely the responsibility of the authors and do not necessarily represent the official views of the National Institute of Environmental Health Sciences or NIH.

\section{References}

1 Rosamond W, Flegal K, Furie K, Go A, Greenlund K, Haase N, Hailpern SM, Ho M, Howard V, Kissela B, Kittner S, Lloyd-Jones D, McDermott M, Meigs J, Moy C, Nichol G, O’Donnell C, Roger V, Sorlie P, Steinberger J, Thom T, Wilson M, Hong Y: Heart disease and stroke statistics - 2008 update: a report from the American Heart Association statistics committee and stroke statistics subcommittee. Circulation 2008;117:e25-e146.

-2 Rosamond WD, Folsom AR, Chambless LE, Wang CH, McGovern PG, Howard G, Copper LS, Shahar E: Stroke incidence and survival among middle-aged adults: 9-year follow-up of the Atherosclerosis Risk in Communities (ARIC) cohort. Stroke 1999; 30:736-743

-3 Carter AM, Catto AJ, Mansfield MW, Bamford JM, Grant PJ: Predictive variables for mortality after acute ischemic stroke. Stroke 2007;38:1873-1880.

.

-4 MacWalter RS, Wong SY, Wong KY, Stewart G, Fraser CG, Fraser HW, Ersoy Y, Ogston SA, Chen R: Does renal dysfunction predict mortality after acute stroke? A 7-year followup study. Stroke 2002;33:1630-1635.

5 Covic A, Schiller A, Mardare NG, Petrica L, Petrica M, Mihaescu A, Posta N: The impact of acute kidney injury on short-term survival in an Eastern European population with stroke. Nephrol Dial Transplant 2008;23: 2228-2234.

-6 Shlipak MG, Sarnak MJ, Katz R, Fried LF, Seliger SL, Newman AB, Siscovick DS, Stehman-Breen C: Cystatin C and the risk of death and cardiovascular events among elderly persons. N Engl J Med 2005;352:20492060.

7 Stevens LA, Coresh J, Greene T, Levey AS: Assessing kidney function - measured and estimated glomerular filtration rate. $\mathrm{N}$ Engl J Med 2006;354:2473-2483.
8 Adams HP Jr, Bendixen BH, Kappelle LJ, Biller J, Love BB, Gordon DL, Marsh EE 3rd: Classification of subtype of acute ischemic stroke: definitions for use in a multicenter clinical trial. Toast. Trial of Org 10172 in Acute Stroke Treatment. Stroke 1993;24:3541.

-9 Levey AS, Coresh J, Greene T, Stevens LA, Zhang YL, Hendriksen S, Kusek JW, Van Lente F: Using standardized serum creatinine values in the modification of diet in renal disease study equation for estimating glomerular filtration rate. Ann Intern Med 2006; 145:247-254.

10 Levey AS, Coresh J, Balk E, Kausz AT, Levin A, Steffes MW, Hogg RJ, Perrone RD, Lau J, Eknoyan G: National kidney foundation practice guidelines for chronic kidney disease: evaluation, classification, and stratification. Ann Intern Med 2003;139:137-147. 
-11 Cowper DC, Kubal JD, Maynard C, Hynes DM: A primer and comparative review of major US mortality databases. Ann Epidemiol 2002;12:462-468.

12 Wentworth DN, Neaton JD, Rasmussen WL: An evaluation of the social security administration master beneficiary record file and the national death index in the ascertainment of vital status. Am J Public Health 1983; 73:1270-1274.

13 Greenland S: Dose response and trend analysis in epidemiology: alternatives to categorical analysis. Epidemiology 1995;6:356-365.

- 14 Anavekar NS, McMurray JJ, Velazquez EJ, Solomon SD, Kober L, Rouleau JL, White HD, Nordlander R, Maggioni A, Dickstein K, Zelenkofske S, Leimberger JD, Califf RM, Pfeffer MA: Relation between renal dysfunction and cardiovascular outcomes after myocardial infarction. N Engl J Med 2004;351: 1285-1295.

15 Fuentes B, Ortega-Casarrubios MA, Martinez P, Diez-Tejedor E: Action on vascular risk factors: importance of blood pressure and lipid lowering in stroke secondary prevention. Cerebrovasc Dis 2007;24(suppl 1):96-106.

16 Kammersgaard LP, Olsen TS: Cardiovascular risk factors and 5-year mortality in the Copenhagen stroke study. Cerebrovasc Dis 2006;21:187-193.

17 Li C, Engstrom G, Janzon L, Hedblad B: Long-term stroke prognosis in relation to medical prevention and lifestyle factors: a prospective population-based study. Cerebrovasc Dis 2008;25:526-532.

18 Astor BC, Hallan SI, Miller ER 3rd, Yeung E, Coresh J: Glomerular filtration rate, albuminuria, and risk of cardiovascular and allcause mortality in the US population. Am J Epidemiol 2008;167:1226-1234.

-19 Goldberg A, Hammerman H, Petcherski S, Zdorovyak A, Yalonetsky S, Kapeliovich M, Agmon Y, Markiewicz W, Aronson D: Inhospital and 1-year mortality of patients who develop worsening renal function following acute ST-elevation myocardial infarction. Am Heart J 2005; 150:330-337.

20 Bertomeu-Gonzalez V, Nunez J, Nunez E, Facila L, Sanchis J, Bodi V, Pellicer M, Bosch MJ, Martinez A, Chorro FJ, Llacer A: Prognostic effect of renal dysfunction after STsegment elevation myocardial infarction with and without heart failure. Int J Cardiol 2006;112:159-165.
-21 Mielniczuk LM, Pfeffer MA, Lewis EF, Blazing MA, de Lemos JA, Shui A, Mohanavelu S, Califf RM, Braunwald E: Estimated glomerular filtration rate, inflammation, and cardiovascular events after an acute coronary syndrome. Am Heart J 2008;155:725731.

22 Dries DL, Exner DV, Domanski MJ, Greenberg B, Stevenson LW: The prognostic implications of renal insufficiency in asymptomatic and symptomatic patients with left ventricular systolic dysfunction. J Am Coll Cardiol 2000;35:681-689.

23 Hillege HL, Nitsch D, Pfeffer MA, Swedberg K, McMurray JJ, Yusuf S, Granger CB, Michelson EL, Ostergren J, Cornel JH, de Zeeuw D, Pocock S, van Veldhuisen DJ: Renal function as a predictor of outcome in a broad spectrum of patients with heart failure. Circulation 2006;113:671-678.

-24 Zhang Q, Ma CS, Nie SP, Du X, Lv Q, Kang JP, Zhang Y, Hu R, Jia CQ, Liu XM, Liu XH, Dong JZ, Chen F, Zhou YJ, Lv SZ, Huang FJ, Gu CX, Wu XS: Prevalence and impact of renal insufficiency on clinical outcomes of patients undergoing coronary revascularization. Circ J 2007;71:1299-1304.

25 Zakeri R, Freemantle N, Barnett V, Lipkin GW, Bonser RS, Graham TR, Rooney SJ, Wilson IC, Cramb R, Keogh BE, Pagano D: Relation between mild renal dysfunction and outcomes after coronary artery bypass grafting. Circulation 2005;112:I270-I275.

26 Cooper WA, O’Brien SM, Thourani VH, Guyton RA, Bridges CR, Szczech LA, Petersen R, Peterson ED: Impact of renal dysfunction on outcomes of coronary artery bypass surgery: results from the Society of Thoracic Surgeons National Adult Cardiac Database. Circulation 2006;113:1063-1070.

-27 Vavlukis M, Georgievska-Ismail LJ, Bosevs ki M, Borozanov V: Predictors of in-hospital morbidity and mortality in patients with coronary artery disease treated with coronary artery bypass surgery. Prilozi 2006;27: 97-113.

28 Zuliani G, Cherubini A, Ranzini M, Ruggiero C, Atti AR, Fellin R: Risk factors for shortterm mortality in older subjects with acute ischemic stroke. Gerontology 2006;52:231236.

-29 Inrig JK, Gillespie BS, Patel UD, Briley LP, She L, Easton JD, Topol E, Szczech LA: Risk for cardiovascular outcomes among subjects with atherosclerotic cardiovascular disease and greater-than-normal estimated glomerular filtration rate. Clin J Am Soc Nephrol 2007;2:1215-1222.

30 Levey AS, Bosch JP, Lewis JB, Greene T, Rogers N, Roth D; Modification of Diet in Renal Disease study group: A more accurate method to estimate glomerular filtration rate from serum creatinine: a new prediction equation. Ann Intern Med 1999;130:461470.
31 Sarnak MJ, Levey AS, Schoolwerth AC, Coresh J, Culleton B, Hamm LL, McCullough PA, Kasiske BL, Kelepouris E, Klag MJ, Parfrey P, Pfeffer M, Raij L, Spinosa DJ, Wilson PW: Kidney disease as a risk factor for development of cardiovascular disease: a statement from the American Heart Association Councils on Kidney in Cardiovascular Disease, High Blood Pressure Research, Clinical Cardiology, and Epidemiology and Prevention. Circulation 2003;108:2154-2169.

32 McCullough PA, Jurkovitz CT, Pergola PE, McGill JB, Brown WW, Collins AJ, Chen SC, Li S, Singh A, Norris KC, Klag MJ, Bakris GL: Independent components of chronic kidney disease as a cardiovascular risk state: results from the Kidney Early Evaluation Program (KEEP). Arch Intern Med 2007;167:11221129.

$\checkmark 33$ Mourad JJ, Pannier B, Blacher J, Rudnichi A, Benetos A, London GM, Safar ME: Creatinine clearance, pulse wave velocity, carotid compliance and essential hypertension. Kidney Int 2001;59:1834-1841.

>34 Ikram MA, Vernooij MW, Hofman A, Niessen WJ, van der Lugt A, Breteler MM: Kidney function is related to cerebral small-vessel disease. Stroke 2008;39:55-61.

35 Hojs Fabjan T, Hojs R, Tetickovic E, Pecovnik Balon B: Ischaemic stroke - impact of renal dysfunction on in-hospital mortality. Eur J Neurol 2007;14:1351-1356

36 Santopinto JJ, Fox KA, Goldberg RJ, Budaj A, Pinero G, Avezum A, Gulba D, Esteban J, Gore JM, Johnson J, Gurfinkel EP: Creatinine clearance and adverse hospital outcomes in patients with acute coronary syndromes: findings from the Global Registry of Acute Coronary Events (GRACE). Heart 2003;89:1003-1008.

>37 Newsome BB, Warnock DG, McClellan WM, Herzog CA, Kiefe CI, Eggers PW, Allison JJ: Long-term risk of mortality and end-stage renal disease among the elderly after small increases in serum creatinine level during hospitalization for acute myocardial infarction. Arch Intern Med 2008;168:609-616.

38 Imai E, Horio M, Nitta K, Yamagata K, Iseki K, Hara S, Ura N, Kiyohara Y, Hirakata H, Watanabe T, Moriyama T, Ando Y, Inaguma D, Narita I, Iso H, Wakai K, Yasuda Y, Tsukamoto Y, Ito S, Makino H, Hishida A, Matsuo S: Estimation of glomerular filtration rate by the MDRD study equation modified for Japanese patients with chronic kidney disease. Clin Exp Nephrol 2007;11:41-50. 